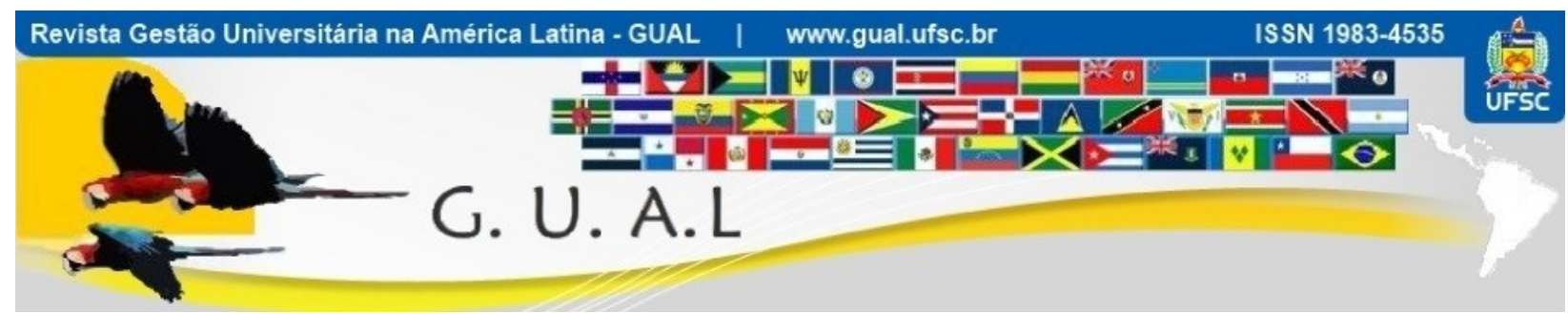

DOI: http://dx.doi.org/10.5007/1983-4535.2015v8n4p1

\title{
REUNI E A FORMAÇÃO ACADÊMICA DOS ESTUDANTES DE SAÚDE DA UFBA: COMPONENTES CURRICULARES, PESQUISA E EXTENSÃO
}

\author{
HEALTH TRAINING AND HIGHER EDUCATION REFORM AT FEDERAL \\ UNIVERSITY OF BAHIA: TEACHING, RESEARCH AND EXTENSION
}

Carolinne Montes Baptista Vieira, Mestre Universidade Federal da Bahia - UFBA carobap@gmail.com

Rafaela Alves Quadros de Araújo, Graduada Universidade Federal da Bahia - UFBA rafa_aqa@hotmail.com

Renata Meira Véras, Doutora Universidade Federal da Bahia - UFBA renata.veras@ufba.br

Recebido em 05/dezembro/2014

Aprovado em 05/abril/2015

Sistema de Avaliação: Double Blind Review

Esta obra está sob uma Licença Creative Commons Atribuição-Uso. 


\title{
RESUMO
}

O presente artigo aponta os resultados de uma pesquisa realizada na Universidade Federal da Bahia (UFBA), referente às percepções dos estudantes dos cursos de saúde, criados a partir do Programa de Apoio a Planos de Reestruturação e Expansão das Universidades Federais (REUNI) sobre os componentes curriculares ofertados, as atividades de pesquisa e extensão. $\mathrm{O}$ objetivo desse estudo foi verificar se houve mudanças na formação dos estudantes que frequentam os referidos cursos de saúde, já que o REUNI propõe uma reformulação curricular e de formação em geral. Os resultados apontam que os estudantes dos cursos de Bacharelado Interdisciplinar em Saúde (BI) são os que mais têm vivenciado as mudanças na formação acadêmica tradicional, demonstrando um maior engajamento em atividades de pesquisa e extensão, bem como lhes tem sido ofertado disciplinas interdisciplinares em institutos diferentes.

Palavras chave: Gestão Universitária. Formação. Ensino. Pesquisa. Extensão.

\begin{abstract}
This article reach the goal to present research results in teaching, research and extension that was development inside Federal University of Bahia (UFBA), Brazil. The aim was verify the changes that occurred after the higher education reform in the context of the health training. The results show that the students of the Bachelor of Science in Interdisciplinary Health Studies experienced changes in the traditional academic training. These students indicate best engagement in research and extension in several university' institutes of The Federal University of Bahia.
\end{abstract}

Key words: University Management. Training. Education, Research, Extension. 


\section{INTRODUÇÃO}

As mudanças nos paradigmas e inovação nas práticas de saúde têm vindo acompanhadas de déficits de adequação, de competência e de motivação dos profissionais de saúde (CARVALHO, 2006). Para este autor, esses profissionais são reféns de graduações cada vez mais distanciadas das necessidades e da dinâmica do trabalho em saúde e são vítimas da falta de políticas qualificadoras do trabalho cotidiano, esses profissionais têm sido muitas vezes relegados pela sociedade a vilões ou cúmplices dos descaminhos da saúde. Portanto, a formação desses profissionais deve envolver um conjunto de variáveis que permitam aliar o domínio da técnica com a capacidade de agir politicamente, com o sentido de garantir que os princípios e as diretrizes que regem o Sistema Único de Saúde sejam preservados e fortalecidos, de maneira que sua implementação aconteça sob os marcos dos direitos sociais e da atenção integral à saúde com equidade e universalidade.

A formação em saúde deve ser um processo crítico e reflexivo que objetive formar profissionais capazes de interpretar, refletir e intervir na dinâmica da saúde/doença dos indivíduos com um olhar mais amplo, observando os aspectos de seu contexto sociocultural e psicológico, e não apenas os aspectos bioquímicos, entendendo que a enfermidade é um processo complexo, que envolve inúmeros fatores.

Nesse sentido, o Governo Federal criou o Programa de Apoio a Planos de Reestruturação e Expansão das Universidades Federais (REUNI) em 2007, tendo como objetivo incentivar as universidades a criarem currículos e projetos acadêmicos que propiciem à flexibilização e o melhoramento da qualidade da educação superior, o aumento de vagas e de número de estudantes, principalmente a permanência dos discentes em estado de vulnerabilidade social (BAPTISTA et al., 2013). Assim, o REUNI, contribuiu para a expansão, democratização e permanência ao ensino superior, criando novos cursos, principalmente no período noturno. Também apresentou como uma importante diretriz a reorganização curricular dos cursos (novos e antigos), adequando-os às necessidades contemporâneas.

Os cursos de saúde criados na UFBA a partir do REUNI no período noturno foram o Bacharelado Interdisciplinar (BI) em Saúde, Biotecnologia, Farmácia, Gastronomia e Saúde Coletiva. No período diurno, foram criados os cursos de Fisioterapia e Zootecnia. Entende-se que os estudantes dessas graduações frequentam a universidade em um momento de transformações após o REUNI, sendo propício conhecer e analisar suas concepções acerca da 
formação que a universidade vem oferecendo e verificar se estão ocorrendo mudanças nessa formação.

É importante destacar que o BI em Saúde foi um curso criado com uma proposta diferenciada da formação acadêmica tradicional até então vigente na UFBA, por comtemplar uma formação geral, caracterizada por um currículo flexível e interdisciplinar, que envolve aspectos do mundo contemporâneo e de diversas áreas do conhecimento, não só saúde, contemplando grande parte das diretrizes do REUNI. Após o término do curso de BI em Saúde, o estudante pode optar em seguir os cursos tradicionais ou cursos de progressão linear (CPL), como também podem optar em ingressar nos cursos de Pós-Graduação.

Dessa forma, esse artigo tem como objetivo investigar as percepções dos estudantes dos cursos de saúde criados no âmbito do REUNI acerca da formação que a universidade vem oferecendo e verificar se estão ocorrendo mudanças nessa formação, saindo de um paradigma tradicional rumo a um novo paradigma na educação, a partir do REUNI.

\section{FUNDAMENTAÇÃO TEÓRICA}

As mudanças ocorridas no mundo global, a nível social, político, tecnológico e econômico, refletem-se na vida cotidiana das pessoas, na realização do trabalho, nas unidades de comércio, nas estruturas empresariais e financeiras, e no setor educacional. Nesse último, o modo de desenvolvimento informacional, utilizado pelos países centrais, tem a característica de aplicar conhecimentos sobre os próprios conhecimentos como principal fonte de produtividade, o que vincula inexoravelmente a educação aos temas da globalização (CASTELLS, 1999).

Nesse contexto, Ortega (2008) observa que a educação vem apresentando uma lacuna cada vez maior, entre o ensino e a realidade, cultivando gradualmente novos elementos para uma realidade que não recua, incluindo a reorientação dos processos na gestão universitária. Diz que as empresas são pró-ativas, enquanto as organizações educacionais são reativas e estão sempre ameaçadas.

Canterle e Favaretto (2008) colocam que nas últimas décadas, o mundo tem se movido em direção a uma sociedade de serviços, onde a universidade é vista como uma instituição de serviços e como espaço de geração e disseminação de conhecimento para a sociedade. 
Nesse sentido, Cazalis (1989) alerta para o desafio de fazer uma gestão em que a instituição participe de redes regionais, nacionais e internacionais, com a finalidade de conjugar esforços para criar programas que melhorem a qualidade dos serviços.

Segundo Desideiro e Ferreira (2004), esse cenário evidencia, portanto, a urgente necessidade de inserir o tema gestão universitária nas discussões organizacionais, face ao seu relevante papel na formação do capital humano que atuará nesta nova realidade.

No final da década de 80, Schrader (1989) apontava que as perspectivas para a educação superior no ano 2000 não seriam promissoras. Vislumbrava a diminuição de pessoas em idade universitária em função do crescimento demográfico, mas um aumento da demanda da pesquisa, extensão e serviços.

Ospina (1990) coloca que a origem e missão primeira das universidades é transformar a sociedade através do conhecimento do potencial humano, sendo suas funções formar ou ensinar, investigar ou pesquisar, e servir ou exercer a atividade de extensão.

De acordo com esta visão, pode-se afirmar que o ensino universitário engloba não só a transmissão do conhecimento em sala de aula, mas a pesquisa, que pode ser pura ou aplicada, e a objetivação desta, através da extensão. Assim, estes três eixos configuram os pilares de sustentação, ou os valores essenciais para que a universidade, como agente de transformação e transmutação, seja preservada (DESIDEIRO; FERREIRA, 2004).

Isto não significa que instituições de ensino sem vinculação com a pesquisa, que basicamente atendem a uma demanda de mercado crescente, ou as chamadas universidades corporativas, como instrumento de geração de conhecimento com fim específico, devam ser desconsideradas. Apenas deve ser questionada a utilização do termo universidade para designá-las, uma vez que não é este o papel a que se propõem (DESIDEIRO; FERREIRA, 2004).

É fato que o aluno que se envolve desde o ínicio de sua formação em atividade de pesquisa e extensão, bem como recebe a oferta de componentes curriculares interdisciplinares, apresenta uma visão mais ampla da saúde e conectada com a realidade.

Nesse sentido, Albuquerque e colaboradores (2007), colocam que a integração entre ensino, pesquisa e a extensão pode contribuir para que seja possível um novo modo de organizar e praticar a atenção à saúde, onde haja um novo perfil de profissionais, qualificados para atender as necessidades da população. Isso requer trabalho em equipe, acolhimento dos usuários, produção de vínculo entre eles e as equipes, responsabilização com a saúde 
individual e coletiva, atendimento das necessidades dos usuários, assim como resolubilidade dos problemas de saúde detectados.

As Diretrizes Curriculares Nacionais dos Cursos de Graduação da área da saúde (DCN), aprovadas entre 2001 e 2004, tem por objetivo construir um perfil acadêmico e profissional que englobe competências, habilidades e conteúdos contemporâneos, bem como, a atuação com qualidade e resolutividade no Sistema Único de Saúde (SUS) (PEREIRA; LOPES; LUGARINHO, 2006).

Para os mesmos autores, as competências gerais desejadas para o graduado nos cursos da saúde consistem em elementos comuns da formação, que são complementadas pelas competências específicas necessárias para cada curso/profissão, onde deve-se priorizar não só o cognitivo, mas o desenvolvimento e incorporação de qualidades técnicas e humanistas. Essas competências devem ser desenvolvidas em todos os níveis, fazendo com que o graduado seja capaz de trabalhar em conjunto com outros profissionais da área de saúde e de valorizar prioritariamente as necessidades de saúde da população, com ênfase na ação preventiva, dentro de uma visão integral e de valores éticos e culturais.

No âmbito da atenção à saúde, as DCN preconizam: os profissionais de saúde devem estar aptos a desenvolver ações de prevenção, promoção, proteção e reabilitação da saúde, tanto em nível individual quanto coletivo. Cada profissional deve assegurar que sua prática seja realizada de forma integrada e continua com as demais instâncias do sistema de saúde. Sendo capaz de pensar criticamente, de analisar os problemas da sociedade e de procurar soluções para os mesmos. Os profissionais devem realizar seus serviços dentro dos mais altos padrões de qualidade e dos princípios da ética/bioética, tendo em conta que a responsabilidade da atenção à saúde não se encerra com o ato técnico, mas sim, com a resolução do problema de saúde, tanto em nível individual como coletivo (PEREIRA; LOPES; LUGARINHO, 2006).

Nessa perspectiva, formar recursos humanos na saúde requer uma parceria entre as políticas das áreas da educação e da saúde, as quais devem estar aliadas a de ciência, tecnologia e inovação em saúde, para atender as necessidades do sistema de saúde, buscando romper com a prática de políticas setoriais isoladas. Isso poderá favorecer o intercâmbio entre os serviços de saúde, as instituições públicas e privadas de ensino superior e as de ciência e tecnologia com vistas à consecução compartilhada de atividades de ensino, pesquisa e extensão nos diversos níveis de atenção à saúde da população, contribuindo incisivamente 
para a discussão que envolve a autonomia universitária e o ordenamento, pelo Sistema Único de Saúde, da formação de seus recursos humanos, como explicitado no Artigo 200 da Constituição Federal (BRASIL, 2006).

O REUNI, através de suas diretrizes II e III, vem contribuir para as Diretrizes Curriculares Nacionais dos Cursos de Graduação da área da saúde.

De acordo ao artigo 2 do decreto, o REUNI possui as seguintes diretrizes:

\footnotetext{
I - redução das taxas de evasão, ocupação de vagas ociosas e aumento de vagas de ingresso, especialmente no período noturno;

II - ampliação da mobilidade estudantil, com a implantação de regimes curriculares e sistemas de títulos que possibilitem a construção de itinerários formativos, mediante o aproveitamento de créditos e a circulação de estudantes entre instituições, cursos e programas de educação superior;

III - revisão da estrutura acadêmica, com reorganização dos cursos de graduação e atualização de metodologias de ensino-aprendizagem, buscando a constante elevação da qualidade;

IV - diversificação das modalidades de graduação, preferencialmente não voltadas à profissionalização precoce e especializada;

V - ampliação de políticas de inclusão e assistência estudantil; e

VI - articulação da graduação com a pós-graduação e da educação superior com a educação básica.
}

No que se refere à importância das atividades de pesquisa e extensão, outro fator também importante corresponde ao ensino, que deve ser voltado para articulação dos saberes nos componentes curriculares.

Pombo (2005), em sua busca de definição para a integração entre os saberes, coloca o conceito de interdisciplinaridade, que seria a convergência e complementaridade disciplinar, que ultrapassa a dimensão do paralelismo de diferentes pontos de vista, e que pode e deve evoluir para uma transdisciplinaridade, onde todo conhecimento se funde e unifica.

Indo nessa direção, Rama (2011) coloca que na América Latina estão se desenvolvendo processos que apontam para a construção de um novo paradigma da formação profissional. Essas mudanças vêm ocorrendo de forma lenta, sendo que o velho paradigma da formação profissional orientada exclusivamente para o grau, de caráter catedrático, tubular e sem flexibilidade, organizado em classes, sem normas mínimas de qualidade, de caráter terminal, sem a existência de estudos posteriores, com exclusiva regulação acadêmica no interior da universidade e de onde o título acadêmico e o título profissional se concedem simultaneamente, está sendo alterado por um novo modelo. Tal modelo introduz o currículo baseado em um enfoque por competências, que se articula através de sistemas nacionais de créditos no interior dos países, que aumenta os níves de flexibilização curricular, que introduz 
sistemas de estágios obrigatórios e créditos de caráter acadêmico, que funciona sobre as bases de normas mínimas de qualidade e se associa a processos de licenciamentos acadêmicos e administrativos, crescentemente dependentes dos Colégios e Associações profissionais prévios ao exercício do trabalho.

O papel do gestor universitário nesse contexto é favorecer e estimular a oferta de componentes currículares interdisciplinares, bem como as atividades de pesquisa e extensão. Deve também promover espaços de diálogos e sensibilização de todos os atores envolvidos neste contexto para sua co-responsabilização no que diz respeito à formação de novos profissionais e à prestação de cuidados em saúde, segundo Albuquerque (2007).

Além disso, é necessário pensar e incentivar a elaboração de metodologias de ensino que incluam mecanismos que visem formar profissionais para o exercício de práticas que estejam mais de acordo com os interesses e necessidades da população. Para uma efetiva e consistente mudança no "modelo de formação dos profissionais de saúde, hoje centrado na atenção à doença" (...) é preciso "garantir a incorporação, nos currículos escolares em todos os níveis de ensino, de conteúdos curriculares sobre o Sistema Único de Saúde, adequando a abertura de cursos na área da saúde às características regionais, sociais, econômicas, epidemiológicas e demográficas" de onde estará localizado o curso (BRASIL, 2006).

O debate em torno dessas ideias na UFBA, nos últimos anos, tem gerado a elaboração de propostas de transformação da arquitetura acadêmica da instituição, com a reformulação da oferta de cursos e a reflexão em torno das possibilidades de introdução de mudanças nos projetos e nas práticas pedagógicas, visando à superação das limitações dos currículos vigentes. Dentre as transformações, houve a criação dos Bacharelados Interdisciplinares, em especial o Bacharelado Interdisciplinar em Saúde (BI Saúde) e a implantação do Instituto de Humanidades, Artes e Ciências Prof.Milton Santos, na gestão do Reitor Naomar de Almeida Filho, no período compreendido entre 2006 e 2008 (ROCHA, et.al, 2012).

Os BI possuem uma estrutura curricular denominada Regime de Ciclos, já adotada pelos modelos mais avançados de educação em saúde do mundo. Como princípio metodológico, os BI adotam modelos pedagógicos ativos e abertos, além de aplicar novas tecnologias de ensino-aprendizagem, disponíveis e testadas em vários momentos da nossa história e em distintos contextos. Desse modo, desenvolve e pratica um sistema de formação com base em métodos e não em conteúdos, com vistas a habilitar o estudante na busca 
permanente de soluções, capacitando-o a continuar aprendendo durante sua futura prática profissional.

\section{METODOLOGIA}

Para investigar as repercussões do REUNI na formação acadêmica dos estudantes dos cursos criados a partir dele na UFBA, utilizou-se a metodologia de pesquisa qualitativa. Os instrumentos utilizados foram entrevistas semiestruturadas que tiveram como base três eixos temáticos: EIXO 1: Oferta de Componentes Curriculares; EIXO 2: Atividades de Extensão e EIXO 3: Atividades de Pesquisa.

Nesses eixos foram levantados alguns aspectos acadêmicos relacionados com a formação dos estudantes, como os componentes curriculares dos cursos de saúde e sua articulação e o desenvolvimento do trabalho dos professores, não só no que compete ao ensino, mas também na realização de atividades de pesquisa e extensão.

As entrevistas foram realizadas com 28 estudantes dos sete cursos de saúde criados no âmbito do REUNI, que são: Bacharelado Interdisciplinar em Saúde, Biotecnologia, Farmácia (noturno), Fisioterapia, Gastronomia, Saúde Coletiva e Zootecnia. Delimitaram-se quatro estudantes por cada curso. Os participantes da pesquisa assinaram o Termo de Consentimento Livre e Esclarecido (TCLE) autorizando sua participação e divulgação das informações prestadas à pesquisa para posterior publicação científica, sendo preservado o sigilo da identidade de cada entrevistado. As respostas dos entrevistados foram gravadas e transcritas. A análise dos resultados encontrados foi organizada em três eixos e os sujeitos da pesquisa foram nomeados por A, B, C, D para cada curso analisado.

\section{RESULTADOS E DISCUSSÃO}

Investigar sobre os componentes curriculares, atividades de pesquisa e extensão dos cursos de saúde na percepção dos estudantes é necessário para fornecer elementos na verificação do cumprimento das diretrizes do REUNI, no que diz respeito à reestruturação acadêmico curricular, bem como verificar como está o entendimento dos estudantes acerca da indissociabilidade entre ensino, pesquisa e extensão.

Assim, serão expostos os resultados da presente pesquisa, através dos três eixos.

\section{EIXO 1: Oferta de Componentes Curriculares}


A oferta de componentes curriculares diante da expansão de matrículas no ensino superior e do contexto contemporâneo requer uma reestruturação, a fim de melhorar o processo formativo na graduação, já que o perfil do estudante nesse cenário tem se modificado qualitativamente e tem requerido maior flexibilidade curricular e possibilidade de diálogo entre as disciplinas, bem como maior liberdade de escolha dos itinerários de formação. No entanto, o que se observa é a presença de uma visão fragmentadora do conhecimento, alienada das questões emergentes da natureza, da sociedade, da história e da subjetividade (BRASIL, 2010).

$\mathrm{Na}$ presente pesquisa foi perguntado aos entrevistados como eles consideravam a oferta de componentes curriculares em seus cursos, sendo solicitado que comentassem um pouco sobre isso. Nas respostas em geral, dos estudantes entrevistados, observa-se que a oferta de componentes é descrita como boa, mas vem acompanhada de pequenas mudanças, no que diz respeito a ofertas em outros institutos que não o dos próprios cursos, bem como componentes de formação geral, como mostram algumas falas:

\footnotetext{
"Eu gosto da oferta de componentes porque temos uma variedade de escolhas, podemos escolher de vários institutos e passar por diversas áreas. Eu acho complicado as vezes montar a grade devido aos horários que sempre chocam, mas com relação a diversidade de componentes eu acho que nós temos diversas escolhas" (estudante B do BI de Saúde).

"Eu acho que a oferta dos componentes curriculares são excelentes creio que ele seje amplo e pegue todos os parâmetros possíveis, desde línguas estrangeiras, como francês, como componentes que enriquece o conhecimento histórico, popular da culinária regional, culinária mundial e traz diversos fatores que vão contribuir para nossa aquisição e nosso conhecimento" (estudante D de Gastronomia).

“(...) é interessante essa disponibilidade de pegar matérias, tanto no nosso curso como em outros cursos também. Eu já peguei matérias em outros cursos e achei fácil pegar, houve a comunicação" (estudante B de Biotecnologia).

"Dos componentes obrigatórios a gente... pelo menos eu acho que tem muita coisa que nunca mais eu vou utilizar na vida, mas por outro lado tem muita coisa que é importante ali você estudar, os componentes de produção de textos acadêmicos em saúde, da uma noção para a gente de muito tipo de produção textual acadêmica, dá uma base para a gente ler e escrever com um pouco mais de conhecimento, ou então tem aquela disciplina saúde, educação e trabalho que também é muito legal, mas ao mesmo tempo teve aquela de língua portuguesa que ninguém sabe nem para que lado vai, nem para que está lá. Das disciplinas que não são obrigatórias tem muita coisa interessante, mas também tem muita coisa que é muito básica"(estudante A do BI de Saúde).
}

Alguns entrevistados comentam que os componentes são engessados e precisam melhorar, bem como o acesso a outros institutos:

"Eu acho um pouco engessada, a gente que veio do BI, a gente tinha acesso a outras
disciplinas em outros Institutos. Aqui em Saúde Coletiva, a gente precisa se dirigir
ao colegiado da matéria, da disciplina que a gente que cursar, a partir de uma 


\title{
REUNI E A FORMAÇÃO ACADÊMICA DOS ESTUDANTES DE SAÚDE DA UFBA: COMPONENTES

liberação deles a gente volta aqui no nosso colegiado para que seja solicitado" (estudante B de Saúde Coletiva).

"A gente mesmo que cheguei do BI, queria, poderia adiantar o meu curso, porque a maioria das minhas optativas já foi resolvida pelo BI. Mas eu não posso porque não há possibilidade de adiantar o curso, fazer em menos tempo" (estudante C de Saúde Coletiva).

Essas respostas mostram que as alunas egressas do BI colocam o currículo como engessado e destacam a burocracia para cursar componente em outro instituto e o fato do colegiado de saúde coletiva não aproveitar disciplinas do BI. É interessante atentar para o fato de que as respostas das alunas egressas do BI podem refletir a visão que adquiriram na formação em um curso de formação geral, como é o BI. A estrutura curricular dos Bacharelados atende a uma perspectiva generalista, interdisciplinar e articulada a diversas modalidades formativas disponibilizadas na universidade (MATOS; SAMPAIO,2013).

Outras respostas também mostram a necessidade de mudanças curriculares:

\begin{abstract}
“(...) mas mesmo assim, ainda existe um déficit não no oferecimento, mas na atualização desses componentes em relação a ementa e a demanda das atualizações na área de saúde mesmo"( estudante B de Fisioterapia).

“(...) é necessário uma base introdutória em Saúde Pública...aproximar um pouquinho a Fisioterapia com a promoção, não só com a reabilitação” (estudante D de Fisioterapia).
\end{abstract}

É relevante observar que essa última colocação veio de um aluno egresso do BI de saúde, o qual teve em sua formação o contato com conteúdos que fazem refletir sobre a promoção da saúde e não apenas a cura de enfermidades. O componente curricular que trata das bases epistemológicas da pesquisa em saúde permite o conhecimento de questões epistemológicas do conhecimento científico no mundo ocidental, focalizando seus efeitos na construção de saberes sobre saúde-doença-cuidado (ALMEIDA FILHO; SANTOS, 2012).

Ainda não há oferta de componentes em outros institutos no curso de Zootecnia, como ilustra a fala do aluno: “A gente só tem aula no nosso Instituto" (estudante A de Zootecnia).

A falta de professores suficientes bem como a dificuldade para conseguir vaga em alguns componentes é mencionada:

\footnotetext{
"Quando a gente precisa de outros componentes curriculares fica muito difícil de conseguir porque as vezes é "muita pouca gente" que precisa e acaba não disponibilizando, por exemplo gastronomia molecular, até hoje não conseguimos uma vaga porque acaba não tendo nem professor, nem aluno suficiente" (estudante A de Gastronomia).

“(...) eu que sempre soube o curso que quer seguir após ser egresso do BI, que é o curso de Medicina, a gente não tem acesso as disciplinas, e por conta disso a gente fica restrito ao $\mathrm{BI}$, sem possibilidade de fazer dispensa das outras disciplinas quando a gente passar para o CPL (estudante C do BI de Saúde).
} 


\section{REUNI E A FORMAÇÃO ACADÊMICA DOS ESTUDANTES DE SAÚDE DA UFBA: COMPONENTES

“(...) a ofertas dos componentes curriculares é um problema pra gente, principalmente do noturno, porque muitas matérias não são ofertadas, no semestre correto, ai acaba que a gente vai acumulando matérias e não consegue se formar, dentro de um prazo né, normal, e o nosso curso já tem um, a matéria já é estendida, o curso de matérias, então isso dificulta muito. E o principal problema dos componentes curriculares é esse, porque tem professor que não quer dar aula dia de sexta-feira, tem professor que não quer dar aula no semestre, ele tem muita disciplina de manhã ai tem que dar aula de noite ai não oferta disciplina ai a gente fica sem sem ter essa disciplina, ai é ruim isso, muito ruim ainda" (estudante A de Farmácia Noturno).

O curso de Farmácia Noturno apresenta maior dificuldade na oferta de vagas nos componentes e na disponibilidade de professores.

Segundo Maranhão; Passos; Véras (2013), o quadro de professores permanentes na UFBA, após o REUNI, teve uma evolução de 32\%, passando para 2.257 professores em 2011 , mas este aumento não alcança a meta, pois apenas 1.675 destes tinham dedicação exclusiva. Isso significa que até 2011 ao invés de serem contratados 470, foram contratados 442 professores com equivalência em DDE. Quanto aos professores substitutos, quadro de 574 existentes em 2006, foi reduzido pela metade em 2011. Talvez essa dinâmica possa ter interferido na contratação de professores e oferta de componentes curriculares.

\section{EIXO 2: Atividades de Extensão}

Segundo Melo Neto (2002), a extensão é um trabalho social, coparticipado, que traz consigo as tensões de seus próprios componentes em ação e da própria realidade objetiva. Um trabalho com o qual se buscam objetos de pesquisa para a realização da construção do conhecimento novo ou novas reformulações das verdades existentes. Esses objetos pesquisados são também os constituintes da outra dimensão da universidade, o ensino. Portanto, a extensão é um trabalho que se realiza na realidade objetiva e é exercido por membros da comunidade, universidade - servidores e alunos. Um trabalho de busca do objeto para a pesquisa e para o ensino, se constituindo como possibilidade concreta de superação da pesquisa e do ensino realizados, mais das vezes, fora da realidade concreta.

Sendo assim, outra pergunta realizada aos estudantes entrevistados foi sobre as atividades de extensão, sendo questionado como eles consideravam essas atividades, se as viam como importantes ou não para a sua formação e se participavam de alguma, sendo solicitado que comentassem um pouco sobre isso. 
Nas respostas dos estudantes pode-se perceber que a maioria reconhece a importância das atividades de extensão, mas poucos participam, sendo que há pouca divulgação dessas atividades.

\footnotetext{
"Acho que faz parte do tripé, ensino, pesquisa e extensão então, (...) então é muito importante para a formação" (estudante D do BI de Saúde).

"Eu não conheço não. Nunca ouvi aqui dentro da UFBA, dentro de gastronomia eu nunca ouvi falar não sobre atividade de extensão. Se já ouvi falaram muito por alto (...) (estudante A de Gastronomia).
}

Quanto a essa falta de divulgação, pode indicar uma falta de atenção ou interesse dos professores em atividades de extensão. Pode também denotar uma deformidade na comunicação entre professores e alunos, como indica Coulon e Pivandi (2008) ao afirmarem ter a impressão de que professores e alunos se comunicam pouco entre si. Alguns alunos veem a extensão como a ligação entre a teoria e a prática, que permite o aprofundamento do conhecimento e que aproxima a universidade da sociedade.

\begin{abstract}
“(...) me trouxe uma carga de conhecimento muito grande e amarra com tudo que a gente aprende que a gente aprende muito a parte teórica, mas quando vai pra prática é outra coisa. O que é ensinado, o que os professores passam, os textos, a gente consegue ver na prática e além da vivencia mesmo (estudante D de Saúde Coletiva). "São extremamente importantes, acredito que a formação atual seja até ultrapassada, agora as atividades de extensão, geralmente, você tem curso, você pode praticar algumas coisas, que na faculdade você não pratica muito, você só começa a pôr em prática o conhecimento que você tem" (estudante A de Biotecnologia).

"É importante porque leva o estudante a ter contato com meio social, com pessoas, não ficar só na vida cientifica mas ter um contato socialmente"(estudante $\mathrm{C}$ de Zootecnia).
\end{abstract}

Outras vezes a confundem com atividades de pesquisa.

“Olha só, eu acho muito interessante atividade de extensão, mas eu não participo de
nenhuma, tanto é que procurei fazer estágio fora da faculdade, porque também
muitas das vezes as atividades de extensão sobrecarrega o aluno por demais, porque
projeto de pesquisa é cansativo e quem gosta da área de pesquisa só tem a crescer,
lógico, só tem a(....)mas eu particularmente não gosto da área de pesquisa. Então as
atividades extensão fora da faculdade é melhor do que aqui” (estudante B de
Farmácia).

Pode-se dizer que as falas de alguns estudantes se relacionam com o pensamento de Forgrad (2000) quando ele afirma que em uma dimensão mais ampla, o ensino, pesquisa e extensão deverão ser indissociáveis, no sentido de desenvolver a noção de cidadania, permitindo atender às demandas da sociedade.

Esse fato vai de encontro ao que foi incluso no artigo 207 da Constituição Federal de 1988 que refere a indissociabilidade entre Ensino, Pesquisa e Extensão, que passa a ser um 
requisito identitário essencial às instituições que querem se firmar como Universidade (MARTINS, 2008).

Além disso, ao analisar as falas dos estudantes e partindo do pressuposto de que a extensão inserida na dinâmica social possibilita ao futuro profissional o exercício político da relação teórico-prático-vivência favorecendo o conhecimento do outro e de si mesmo e na formação de valores e atitudes de solidariedade, sensibilidade e amor, dimensões essenciais da formação integral, percebe-se nos estudantes entrevistados, mesmo sem participar atualmente de nenhuma atividade de extensão vão de encontro ao pensamento de Weber (2000), de que as atividades de extensão configuram-se como elo entre o aprendizado em sala de aula e a prática intervencionista qualificada e qualificadora.

\section{ATIVIDADES DE PESQUISA}

A pesquisa visa gerar conhecimento sobre algo para que alguém possa conhecer tal coisa. Não se faz pesquisa sobre o já comprovado, exceto para refutar. A pesquisa científica visa à produção de conhecimento novo, relevante teoricamente, fidedigno e útil socialmente (LUNA, 1999).

Portanto é necessário a pesquisa e essa deve começar já no âmbito da graduação. Sendo assim, a terceira questão da entrevista questionava os estudantes sobre a importância das atividades de pesquisa em sua formação e se participa de alguma, solicitando que falassem um pouco sobre isso.

Em relação a importância das atividades de pesquisa, os alunos reconhecem a sua importância, mas a maioria não participa de nenhuma atividade dessa natureza.

\footnotetext{
"Eu não participo de nenhuma, mas eu acho que é importante até os professores virem incentivando a gente a fazer alguns tipos de pesquisa, até mesmo artigo científico, essas coisas. Os professores tentam sempre passar para a gente ler, saber, porque é uma forma da gente aprender o que... melhorando o nosso próprio conhecimento e é isso...(estudante A de Gastronomia).

"Acho muito importante, porque sem a ciência não é possível fazer nada, sempre bom ficar pesquisando, estudando novas tecnologias para poder descobrir novas possibilidades de solucionar problemas. Não participo não" (estudante C de Zootecnia).

"Extremamente importantes, não tem como o aluno entrar na Universidade e não conhecer a Universidade em si, acho que entrar numa pesquisa é conhecer esse mundo cientifico, que é extremamente importante" (estudante A de Biotecnologia).
}

A pesquisa é vista como um elo de ligação entre a teoria e a prática e como ampliadora do conhecimento.

“(...) Porém, pesquisa é porque você pega a prática, não é só teoria, é você botar o que você aprendeu na prática” (estudante C de Biotecnologia). 
"Eu acho que pesquisa é importante pois gera conhecimento prático. Você acaba aprendendo tanto o teórico quanto o prático dentro da pesquisa e isso, eu não sei, engradece o currículo, tudo mais, transforma sua visão" (estudante C de Fisioterapia).

“(...) a pesquisa eu acho que é essencial porque vai trazer um conhecimento a mais, cultural, vai trazer conhecimento crítico para a gente poder desenvolver nossas habilidades"(estudante D de Gastronomia).

"Acho que faz parte do tripé, ensino, pesquisa e extensão então, (...) então é muito importante para a formação" (estudante D do BI de Saúde).

A pesquisa às vezes é percebida como um estudo exaustivo.

“ (...) Divulgam só entre e-mail, mas nunca falam em sala de aula. Deveriam falar, deveria incentivar... ai falta muito... acaba que pouca gente fica sabendo mesmo e nem todo mundo tem coragem de sentar e ficar horas estudando para poder conseguir fazer alguma coisa" (estudante C de Gastronomia).

“ (...) já vi colegas fazendo algumas, é uma correria "retada", eu acho que isso é legal você aprende muito, mas assim, se é essencial para sua formação eu diria que não é, eu acho que incremente, melhora muito sua formação. Uma vez fui para reunião que a professora fez para chamar para participar da atividade de pesquisa(...) eu entendi o que era atividade de pesquisa, eu percebi que eu não ia ter tempo para aquilo, que a atividade de pesquisa consome muito de você e ela, a atividade de pesquisa eu teria que ir em vários lugares distantes de minha casa, eu rodar muito, ler muito e eu sabia que eu não ia ter a capacidade de fazer a atividade de pesquisa e fazer bem as minhas disciplinas, ai eu preferi naquele momento, pelo menos, não fazer" (estudante A do BI de Saúde).

Observa-se nas falas dos estudantes que eles compreendem o que seja a pesquisa, associam-na com a prática do que aprendem em sala de aula, e nesse ponto coincidem com as respostas dadas na pergunta anterior, sobre as atividades de extensão. No entanto, a participação em atividades de pesquisa é muito pequena, o que mostra a falta de disponibilidade dos estudantes para realiza-las, bem como talvez o pouco incentivo dos professores da universidade nessas atividades, como mostrou a fala de alguns estudantes.

Contudo, o aluno deve ser estimulado a produzir trabalhos acadêmicos que propiciem o desenvolvimento de um conjunto de competências no campo da sua futura atuação profissional através de uma maior compreensão entre a realidade prática e a teoria apreendida em sala de aula. Assim, a produção de conhecimento não pode estar dissociada da prática da pesquisa (PRADO, 2013).

\section{CONCLUSÃO}

Com relação aos componentes curriculares dos cursos de saúde oriundos do REUNI, pode-se identificar nas respostas dos entrevistados que a maioria considera a oferta boa, suficiente, no entanto alguns relatam que há dificuldade em se matricular em alguns componentes, pela burocracia, requisitos exigidos e pela falta de vagas em alguns 
componentes de alguns institutos. Outras respostas, embora poucas, mostram que a qualidade dos conteúdos dos componentes é insuficiente para a realidade da profissão, sendo que apenas os entrevistados egressos do BI de Saúde e os que cursam atualmente o referido BI, comentaram sobre a presença de componentes interdisciplinares e mobilidade entre institutos, o que mostra a atuação das diretrizes do REUNI na mudança do modelo acadêmico vigente tradicional no curso de BI em Saúde.

As atividades de extensão são consideradas importantes na formação pela grande maioria dos entrevistados, sendo considerada uma atividade que leva à prática da profissão e complementa a teoria. Apenas um estudante egresso do BI comentou sobre a importância social da extensão, que leva o aluno para a realidade social. Alguns alunos entrevistados já fizeram ou fazem extensão, mas é um número muito pequeno, o que mostra que essas atividades ainda são pouco vivenciadas pelos estudantes e algumas respostas denotam a necessidade de serem melhor divulgadas e de propiciar tempo para os estudantes realizarem a extensão, já que alguns trabalham e tem agrade curricular muito extensa.

No que se refere as atividades de pesquisa, essas também são consideradas muito importantes na formação, por enriquecer o currículo, aproximar mais a teoria da prática, estimular o senso crítico e as habilidades de escrita, estudo. No entanto ainda são poucos os entrevistados que participam ou participaram de atividades de pesquisa, sendo que o contingente maior de participantes nessas atividades, são estudantes egressos do BI, o que pode indicar a influência da formação geral dada no BI na participação em atividades de pesquisa.

Nas três esferas ensino, pesquisa e extensão, notou-se nas respostas à pesquisa que os professores são apontados como agentes de incentivo e promoção de oferta de componentes curriculares, atividades de pesquisa e extensão, o que muitas vezes não ocorre, principalmente com relação as atividades de extensão. Em nenhum momento os entrevistados mencionaram o papel da gestão universitária nesse processo.

Portanto, observa-se uma mudança na formação dos alunos dos Bacharelados Interdisciplinares em Saúde, no que se refere ao cumprimento das diretrizes do REUNI. Nos demais cursos, isso não ficou evidente, o que aponta a necessidade da gestão universitária da UFBA ser mais ativa na promoção de mudanças no paradigma de educação oferecida nessa universidade. 


\section{REFERÊNCIAS}

ALBUQUERQUE et al. A Integração Ensino-serviço no Contexto dos Processos de Mudança na Formação Superior dos Profissionais da Saúde. Revista Brasileira de Educação médica vol. 32 (3): 356-362; 2008.

ALMEIDA FILHO, N.; SANTOS, V.P. Seminários interdisciplinares de pesquisa em saúde: debatendo as bases epistemológicas das ciências no Bacharelado Interdisciplinar em Saúde. In: TEIXEIRA, C.F.; COELHO, M.T.A.D. Bacharelado Interdisciplinar em Saúde: uma experiência inovadora no ensino superior.2012.

BAPTISTA et al., O Estado da Arte sobre o Reuni, XIII Colóquio de Gestão Universitária, rendimentos Acadêmicos e eficácia social das Universidades nas Américas, Buenos Aires, 2013.

Ministério da Educação. REUNI - Reestruturação e Expansão das Universidades Federais: diretrizes gerais (Documento Elaborado pelo Grupo Assessor nomeado pela Portaria $n^{\circ} 552$ SESu/MEC, de 25 de junho de 2007, em complemento ao art. $1^{\circ} \S 2^{\circ}$ do Decreto Presidencial no 6.096, de 24 de abril de2007). Brasília, 2007.

BRASIL. Ministério da Saúde. Fundação Oswaldo Cruz. Dinâmica das graduações em saúde no Brasil: subsídios para uma política de recursos humanos / Ministério da Saúde, Fundação Oswaldo Cruz. - Brasília: Ministério da Saúde, 2006.

BRASIL. Ministério da Educação. Secretaria de Educação Superior. Referenciais Orientadores para os Bacharelados Interdisciplinares e Similares. Disponível em: reuni.mec.gov.br. Brasília, 2010. Acesso em 19 Set.2013.

CANTERLE, N.M.G; FAVARETTO, F. Proposta de um modelo referencial de gestão de indicadores de qualidade na instituição universitária. Ensaio: aval.pol.públ.Educ. [online]. 2008, vol.16, n.60, pp. 393-412. ISSN 0104-4036

CASTELLS, Manuel. A sociedade em rede. Vol. I. São Paulo: Paz e Terra, 1999.

CAZALIS, P. La Universidad del Año 2000 - un perfil reequilibrado. In: VAHL, Rogério Teodoro; MEYER JR, Victor; FINGER, Almeri Paulo (organizadores). Desafios da Administração Universitária. Seminário Internacional de Administração Universitária. Florianópolis: UFSC, 1989.

COULON, A.; PAIVANDI, S. Les relations entre les étudiants, les enseignants et le personnel non-enseignant dans les établissements supérieurs em France. Paris: Observatoire Nationale de la Vie Étudiante, 2008.

DESIDEIRO, M; FERREIRA, A.P.F. Desafios da gestão universitária. Resende, 2004.

FORGRAD - Fórum de Pró-Reitores de Graduação das Universidades Brasileiras. Plano Nacional de Graduação: um projeto em construção, forgrad, 2000. 
LUNA, S.V. Planejamento de pesquisa - Uma introdução. São Paulo, EDUC:1999.

MACEDO, B.T.F; VERAS, R.M; LEMOS, D. A Trajetória da Criação dos Bacharelados Interdisciplinares na Universidade Federal da Bahia. Revista Avaliação, Campinas, 2013.

MARANHÃO, J.D; PASSOS, W.S; VERAS, R, M. Adesão da UFBA ao REUNI e a nova modalidade curricular: os Bacharelados Interdisciplinares. Anais do VI Colóquio Internacional de Políticas e Práticas Curriculares, 2013, p.1607-1623.

MARTINS, E.F. Extensão como componente curricular: oportunidade de formação integral e de solidariedade. Revista Ciências \& Cognição. Vol 13 (2): 201-209, 2008.

MATOS, R.L; SAMPAIO, S. M. R. A Orientação Acadêmica entre a disciplinaridade e a interdisciplinaridade. In: SANTOS, G.G.; SAMPAIO, S.M.R. Observatório da Vida Estudantil: Universidade, Responsabilidade Social e Juventude. Salvador: Edufba, 2013.

MAZONI, I; CUSTÓDIO, L; SAMPAIO, S.M.R.O Bacharelado Interdisciplinar da Universidade Federal da Bahia. O que dizem os estudantes? In: SAMPAIO, S.M.R. (Org.). Observatório da Vida Estudantil. Primeiros Estudos. Salvador: Edufba, 2011. p. 229248.

MELO NETO, J. Extensão Universitária: bases ontológicas. João Pessoa: Editora Universitária, 2002.

ORTEGA, Alfredo. Percepción de los Gerentes Educativos sobre la Productividad Académica en el Ejercicio de Funciones Administrativas: Estudio de Casos. Investigación y Postgrado. dez. 2008, vol.23, no.3, p.345-357. Disponível

em: $<$ http://www.scielo.org.ve/scielo.php?script=sci_arttext\&pid=S131600872008 0300016\&lng=pt\&nrm=iso $>$. ISSN 1316-0087.

OSPINA, G. L. Definição de uma agenda para o ensino superior nos anos 90. In: Crub. Universidade, Estado e Sociedade na década de 90. Brasília, 1990.

PEREIRA, L.A.; LOPES, M. G.K.; LUGARINHO, R. VII Congresso Nacional da Rede Unida. "Promover saúde e impulsionar mudanças na formação profissional e no cuidado à saúde: uma política de Estado." Termo de Referência - Oficina 1 Diretrizes curriculares nacionais e níveis de atenção à saúde: como compatibilizar? Curitiba, 2006.

POMBO, O. Interdisciplinaridade e integração dos saberes. Liinc em rev. [periódico na Internet]. 2005. Acesso em julho/2014. Disponível em: http://www.liinc.ufrj.br/revista

PRADO, M.R. Pesquisa como estratégia de ensino: uma proposta inovadora em faculdades privadas. Revista Ensino Superior n ${ }^{\circ} 11$ out-dez, 2013.

RAMA, C. Paradigmas emergentes, competências profisionales y nuevos modelos universitários em América Latina. San Luis: Nueva Editorial Universitaria: 2011. 
ROCHA, M.N.D. Educação superior em saúde: contexto institucional de criação do bacharelado interdisciplinar. In: TEIXEIRA, C.F.; COELHO, M.T.A.D. Bacharelado Interdisciplinar em Saúde: uma experiência inovadora no ensino superior.2012.

SCHRADER. As Universidades na República Federal da Alemanha Rumo ao Ano 2000. In: VAHL, Teodoro Rogério et al. Desafios da Administração Universitária. Seminário Internacional de Administração Universitária (1989). Florianópolis: Ufsc, 1989.

WEBER, S. (2000). Políticas do ensino superior: perspectivas para a próxima década. Avaliação, v.6 (1), 15-18. 